\title{
Mosaic UPD(7q)mat in a patient with silver Russell syndrome
}

\author{
Jiasun Su${ }^{1 *}$, Jin Wang ${ }^{1}$, Xin Fan ${ }^{1}$, Chunyun Fu', ShuJie Zhang ${ }^{1}$, Yue Zhang ${ }^{1}$, Zailong Qin ${ }^{1}$, Hongdou Li ${ }^{1}$, Jingsi Luo ${ }^{1}$, \\ Chuan $\mathrm{Li}^{1}$, Tingting Jiang ${ }^{1}$ and Yiping Shen ${ }^{1,2^{*}}$
}

\begin{abstract}
Background: Silver-Russell syndrome (SRS) is one of the imprinting disorders characterized by prenatal and postnatal growth restriction, relative macrocephaly, body asymmetry and characteristic facial features. $\sim 10 \%$ of SRS cases are known to be associated with maternal uniparental disomy of chromosome 7 (UPD(7)mat). Mosaic maternal segmental UPD of 7q (UPD(7q)mat) is very rare, had only been described in one case before.

Case presentation: We reported a second case of mosaic segmental UPD involving 7q. The patient presented with dysmorphic features including thin and short stature, triangular face, moderate protruding forehead, relative macrocephaly, fifth toe clinodactyly and irregular teeth, meeting the clinical diagnosed criteria of SRS. This case indicated that $\sim 80 \%$ of mosaic UPD(7q)mat lead to the manifestation of main phenotypes of Silver-Russell syndrome.

Conclusions: Our case support the notion that there are genes control postnatal growth on long arm of chromosome 7 and indicate that $~ 80 \%$ of UPD(7q)mat mosaicism level was contributed to the SRS phenotype.
\end{abstract}

Keywords: Silver-Russell syndrome, Maternal uniparental disomy, Mosaicism

\section{Background}

The Silver-Russell syndrome (SRS; OMIM \#180860) is one of the imprinting disorders characterized by prenatal and postnatal growth restriction, relative macrocephaly, body asymmetry and characteristic facial features. To date, more than 400 SRS cases have been reported since it was initially described by Silver et al. in 1953 [1] and Russell in 1954 [2]. The clinical and genetic heterogeneity of SRS make it difficult to define its clinical diagnostic criteria and genetic etiology. Several scoring systems for clinical diagnosis of SRS have been proposed [3-7]. Most recent proposal suggested that a patients can be considered to have likely SRS if at least four out of the following six criteria were met: (1) small for gestational age, birth length and/or weight $\leq-2$ SDS, (2) postnatal growth retardation (height $\leq-2 \mathrm{SDS}$ ), (3) relative macrocephaly at birth, (4) body asymmetry, (5) feeding difficulties and/or body mass index $(\mathrm{BMI}) \leq-2 \mathrm{SDS}$ in toddlers; (6) protruding forehead at the age of 1-3 years (Netchine-

\footnotetext{
* Correspondence: sujiasun@126.com; yiping.shen@childrens.harvard.edu ${ }^{1}$ Department of Genetic and Metabolic Central Laboratory, Guangxi Maternal and Child Health Hospital, Guangxi Birth Defects Prevention and Control Institute, No 59, Xiangzhu Road, Nanning, China

Full list of author information is available at the end of the article
}

Harbison SRS Clinical Scoring System). About 10\% of SRS case had maternal uniparental disomy of chromosome 7 , so far about 60 SRS patients with matUPD(7) had been reported [8]. The imprinting genes on chromosome 7 are believed to be involved in the pathogenesis of the syndrome [9-13], the specific causal gene(s) are yet to be identified.

Five cases with segmental UPD(7q)mat in patients with SRS phenotype had been documented in literature since 2001. The only mosaic segmental UPD(7) that was reported by Reboul et al. in 2006 revealed a 7q21-qter mosaicism in a patient with SRS phenotype [14]. Identifying segmental UPD(7) in patients with SRS may help to narrow-down causal genes and regions.

Here, we reported a second case with mosaic segmental $\operatorname{UPD}(7 \mathrm{q})$ mat, the patient presented with the main phenotypes of SRS [15]. We compared the clinical findings involving mosaic UPD(7q)mat documented in literature and the finding support the notion that imprinted genes on 7q contribute to the pathogenesis of SRS, even in a mosaic status. 


\section{Case presentation}

The patient was a six-year-old boy came to hospital due to severe developmental delay, short stature and mild dysmorphic features. He was a full term first child with two apparently healthy younger siblings. He was delivered via cesarean section without complication during pregnancy or delivery. His birth weight was $1.91 \mathrm{~kg}(<$ $-3 S D)$, indicating small for gestational age. His parents were non-consanguineous without family history of congenital anomalies. The paternal height was $162 \mathrm{~cm}$, and the maternal height was $138 \mathrm{~cm}$, the mother was not investigated for SRS and the height of the maternal familily members were not applied. The patient was reported to have failure to thrive since birth. During his initial hospital visit at the age of 6 , his height was $91.9 \mathrm{~cm} \mathrm{(} \mathrm{-}$ $6 \mathrm{SD})$, weight $9.5 \mathrm{~kg}(\sim-6 \mathrm{SD})$ and head circumference $49 \mathrm{~cm}(\sim-1 \mathrm{SD}$, thus a relative macrocephaly). The bone age was delayed. Mild dysmorphic features were noticed including triangular face, moderate protruding forehead, relative macrocephaly, fifth toe clinodactyly and irregular teeth (Fig. 1a). Although the obvious body asymmetry was not noticed in this patient, this patient can be clinical diagnosed as SRS based on the Netchine-Harbison clinical scoring system (the first four features are present in this patient) [16]. In addition, he had normal electroencephalogram and electromyography, the growth hormone $(\mathrm{GH})$ stimulating peak was $5.08 \mu \mathrm{g} / \mathrm{L}$ and diagnosed as partial growth hormone deficiency. He was subsequently treated with recombinant human growth hormone at the doses of $1 \mathrm{IU} /(\mathrm{kg} / \mathrm{d})$. The treatment lasted
4 months and stopped due to no significant growth response. Cytogenetic and molecular analysis were performed.

\section{Method}

Chromosomal microarray (CMA) and cytogenetic analyses DNA sample was extracted from peripheral blood lymphocytes by using Lab-Aid DNA kit (Zeesan Biotech Co, Ltd., China). Genomic wide single nucleotide polymorphism (SNP) array analysis was performed by Illumina HumanSNPcyto-12 v2.1 BeadChip array. And the SNP data were collected and analyzed by Illumina Genome Studio and KaryoStudio software, cytogenetic analysis was performed by conventional standard GTG-banding at $400-550$ band resolution.

\section{Microsatellite analysis}

Eight highly informative microsatellite markers (short tandem repeat, STR) spanning the whole of chromosome 7 (D7S2552, D7S506, D7S510, D7S517, D7S672, D7S2410, D7S2504, D7S523) were selected from Genethon Genetic Maps (http://www.bli.uzh.ch/BLI/Projects/ genetics/maps/gthon.html) for parent-of-origin analysis. The forward PCR primers designed for each STR maker were modified at $5^{\prime}$ terminal base with carboxyfluorescein (FAM). All fluorescent PCR products were analyzed on ABI 3130 genetic analyzer and GeneMapper (Applied Biosystems), the size and loci of each STR marker was assigned manually by identifying the peak on the electropherogram. a

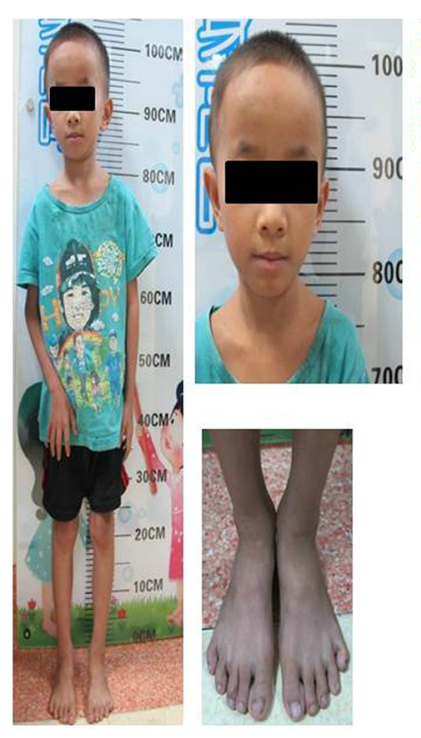

b

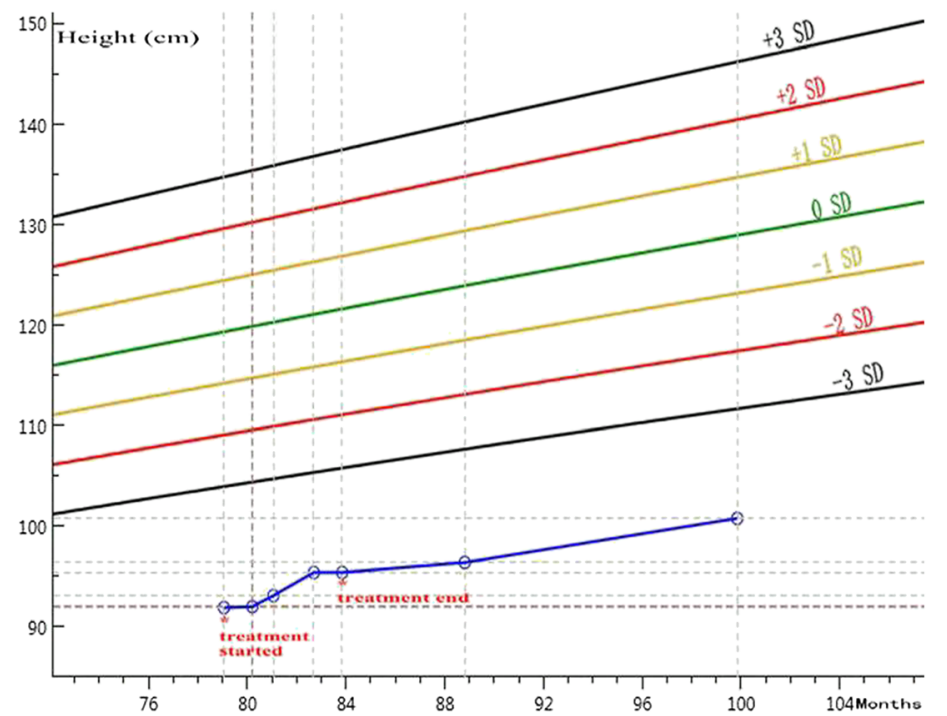

Fig. 1 a Patient at age 8 years and 3 months. Dysmorphic features including thin and short stature, triangular face, moderate protruding forehead, relative macrocephaly, fifth toe clinodactyly and irregular teeth. $\mathbf{b}$ Growth curve of the patient: standard deviations (SD) were calculated based on the standardized growth charts for Chinese children and adolescents aged 0 to 18 [33], according to population-standard charts, the patient's growth improved but remained $\sim 5.5$ SD below the mean height for age 


\section{Results}

Uniparental disomy (UPD) of chromosome $7 \mathrm{q}$ was detected by CMA, spanned from the region of $7 q 11$ to 7qter. The B allele frequency indicated that the UPD region was homozygous and mosaic (Fig. 2a), and the mosaicism level was estimated to be about $80 \%$ according to Conlin et al. [17]. G-band analysis presented normal karyotype. The STR makers analysis revealed that the UPD was maternal origin (Fig. 2b, c).

\section{Discussion}

We reported a rare case of SRS due to mosaic segmental $\mathrm{UPD}(7 \mathrm{q}) \mathrm{mat}$. This is only the second such case ever reported [14] and the first case detected by SNP array. There are more than $60 \mathrm{UPD}(7)$ mat cases documented in the literature since the first case of UPD(7)mat reported by Spence et al. $[8,18]$, we summarized the clinical features of typical SRS features and UPD(7)mat cases in Table 1 . The body asymmetry phenotype was only $\sim 39 \%$ prevalent among SRS cases. Relative macrocephaly (79.2\%), SGA, BL and/or BW (61.6\%), prominent forehead (61.6\%), clinodactyly $\mathrm{V}$ digits (57.0\%), feeding difficulties (46.5\%), were the most common phenotype in the UPD(7)mat cases. Our patient presented with at least four common features, thus meet the clinical diagnosis of SRS (Netchine-Harbison SRS Clinical Scoring System, NH-CSS) [3].

Mosaic UPD(7)mat was a rare condition. Monk et al. did not find any evidence of somatic mosaicism in three UPD(7)mat probands in lymphocyte and fibroblasts using both Southern blot and FISH analyses [19], subsequently, five mosaic UPD(7) mat cases have been reported (Table 2). Karl Y et al. found the first case of trisomy 7 (T7)/upd(7) mosaicism by amniocentesis, and the fetus showed likely-SRS symptoms with SGA, lowset ears, prominent forehead, triangular face, obstructed micrognathia, clinodactyly of fifth finger bilaterally [20]. Miozzo et al. used haplotyping and cytogenetic-FISH studies characterized a newborn presented SRS phenotype with complete maternal isodisomy 7 (i7) and trisomy 7 mosaicism [21]. Complete maternal heterodisomy 7 and trisomy 7 mosaicism was also reported by Elisabeth et al. [22]. Patient with full UPD(7) mat abnormal cell lineage and normal cell lineage without trisomy 7 also present SRS phenotype [23]. Reboul et al. reported a patient had UPD (7) without the mosaic trisomy 7 [14]. A summary of

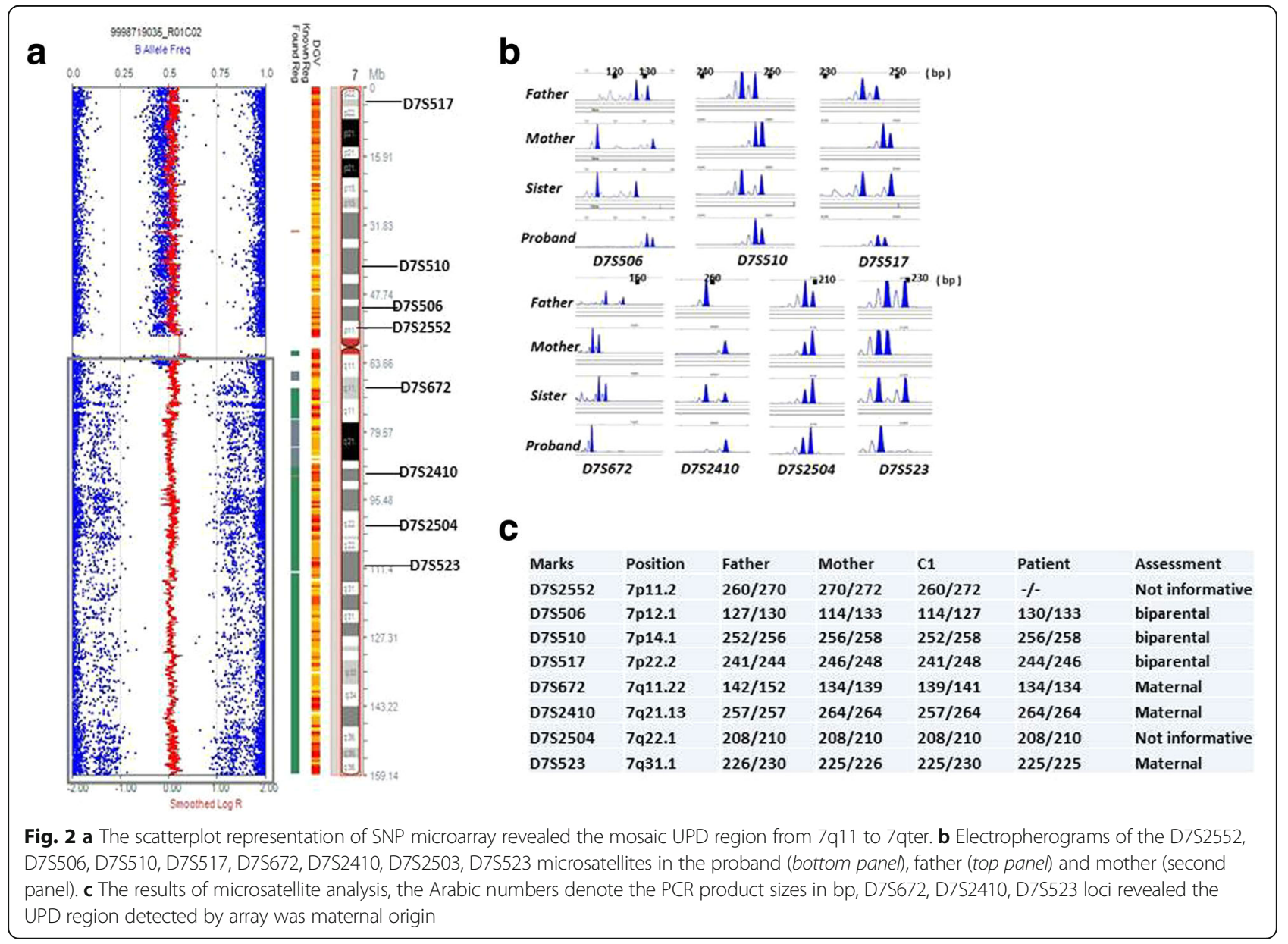


Table 1 Phenotypic comparison of typical SRS cases and SRS due to UPD(7) mat

\begin{tabular}{|c|c|c|c|c|}
\hline Clinical findings & $\begin{array}{l}\mathrm{SRS}^{a} \\
(\mathrm{NH}-\mathrm{CSS})\end{array}$ & UPD(7) mat cases ${ }^{b}$ & $\begin{array}{l}\text { mosaic UPD(7) mat cases }{ }^{c} \\
n=5\end{array}$ & Our patien \\
\hline Relative macrocephaly & + & $61 / 77(79.2 \%)$ & 3 & + \\
\hline $\mathrm{SGA}, \mathrm{BL}$ and/or $\mathrm{BW} \leq-2 \mathrm{SD}$ & + & $53 / 86(61.6 \%)$ & 5 & + \\
\hline Asymmetry & + & 30/77(39.0\%) & 1 & - \\
\hline Feeding difficulties & + & $40 / 86(46.5 \%)$ & 2 & - \\
\hline Retarded bone age & + & $24 / 77(31.2 \%)$ & 1 & + \\
\hline Clinodactyly V digits & $75 \%$ & 49/86(57.0\%) & 3 & + \\
\hline Triangular face & $94 \%$ & $24 / 86(28.0 \%)$ & 3 & + \\
\hline prominent forehead & + & $53 / 86(61.6 \%)$ & 3 & + \\
\hline Teeth anomalies & $37 \%$ & 14/77(18.2\%) & 1 & + \\
\hline Low set ears & $49 \%$ & $16 / 68(23.5 \%)$ & 2 & - \\
\hline small chin & $62 \%$ & 10/86(11.6\%) & 1 & + \\
\hline
\end{tabular}

Clinical findings: + , present; -, absent, SGA small for gestational age, $B L$ birth length, $B W$ birth weight $\mathrm{NH}$-CSS netchine-harbison SRS clinical scoring system

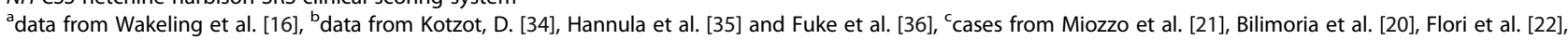
Reboul et al. [14], and Tomoko et al. [23]

the clinical features of the five previously reported patients with mosaic UPD(7)mat and our present case is listed in Table 2. Collectively, these cases indicated that SRS phenotype could raise from mosaic UPD(7)mat status.

Five segmental UPD(7q) mat cases associated with SRS phenotypes had been documented in literature since 2001 [14, 24-26] (Table 3). The involved region would span the whole $7 \mathrm{q}$ and the smallest region was $\sim 31 \mathrm{Mb}$ to 7qter (Fig. 3). Clinical features of segmental $\mathrm{UPD}(7 \mathrm{q})$ mat were compared in Table 3 . The most common were relative macrocephaly and triangular face (5/ 5). Notably, psychomotor delay was present in the case reported by Eggermann et al. [25] and Begemann et al.
[26], but not in the rest of cases. Additionaly, The relevance of $7 \mathrm{p}$ for the SRS phenotype currently known are maternal duplication of $7 \mathrm{p} 12.1$ (including gene GRB10) $[27,28]$, These findings are consistent with the notion that the imprinted gene(s) on chromosome $7 \mathrm{q}$ are the causes of SRS phenotype [9].

The only previously reported a mosaic segment UPD (7q)mat from 7q21-qter mosaicism by Reboul et al. in a patient presented with SGA, relative macrocephaly, triangular face, severe growth retardation [14]. Our patient had only slightly larger size and presented with very similar phenotypes. The mosaicism level of Reboul's case was not evaluated.

Table 2 Clinical features of mosaic UPD(7) mat cases

\begin{tabular}{|c|c|c|c|c|c|c|}
\hline & Miozzo et al. & Bilimoria et al. & Elisabeth et al. & Reboul et al. & Tomoko et al. & Our patient \\
\hline $\begin{array}{l}\text { Mosaicism } \\
\text { UPD type }\end{array}$ & $\begin{array}{l}\text { Mixture of i7 } \\
\text { andT7 }\end{array}$ & Mixture of i7 and T7 & Mixture of het 7 and T7 & $\begin{array}{l}\text { Mosaic } \\
\text { segmental } \\
\text { UPD7(q21-qter) }\end{array}$ & $\begin{array}{l}\text { Mixture of i7 } \\
\text { and N7 }\end{array}$ & $\begin{array}{l}\text { Mosaic UPD7 } \\
\text { (q11-qter) }\end{array}$ \\
\hline $\begin{array}{l}\text { Evaluation } \\
\text { analysis }\end{array}$ & $\begin{array}{l}\text { Microsatellite } \\
\text { Metaphase FISH } \\
\text { karyotyping }\end{array}$ & $\begin{array}{l}\text { Microsatellite, } \\
\text { karyotyping }\end{array}$ & Microsatellite, FISH & microsatellite analysis & $\begin{array}{l}\text { microsatellite } \\
\text { karyotype } \\
\text { methylation }\end{array}$ & $\begin{array}{l}\text { SNP array } \\
\text { microsatellite }\end{array}$ \\
\hline tissuses & $\begin{array}{l}\text { Peripheral blood } \\
\text { placental } \\
\text { cotyledons }\end{array}$ & $\mathrm{AF}: \sim 27 \%^{\mathrm{a}}$ & $\begin{array}{l}\text { AF: 44\% Intestine: } \\
\text { 15\% Skin: metaphases } \\
(5.5 \%)=\text { nuclei }(4 \%)\end{array}$ & Peripheral blood & $\begin{array}{l}\text { Peripheral blood: } \\
\text { 92\% Salivary:91\% }\end{array}$ & $\begin{array}{l}\text { Peripheral blood: } \\
\sim 80 \%\end{array}$ \\
\hline $\begin{array}{l}\text { Major } \\
\text { Clinical } \\
\text { findings }\end{array}$ & $\begin{array}{l}\text { IUGR, low birth } \\
\text { weight, PNGR, } \\
\text { relative } \\
\text { macrocephaly, } \\
\text { triangular face, } \\
\text { prominent } \\
\text { forehead, } \\
\text { asymmetry }\end{array}$ & $\begin{array}{l}\text { SGA, low-set ears, } \\
\text { prominent forehead, } \\
\text { small chin, triangular } \\
\text { face, micrognathia, } \\
\text { reversed epicanthal } \\
\text { folds, clinodactyly of } \\
\text { fifth finger bilaterally }\end{array}$ & $\begin{array}{l}\text { Prominent large } \\
\text { forehead, low osterior- } \\
\text { rotated ears, small and } \\
\text { retruded chin, bilateral } \\
\text { clinodactyly of fifth } \\
\text { fingers, VSD, PNGR, } \\
\text { relative macrocephaly, } \\
\text { feeding difficulties, } \\
\text { triangular-shaped face, } \\
\text { BAD }\end{array}$ & $\begin{array}{l}\text { Growth failure, SGA, } \\
\text { low birth weight, not } \\
\text { show any craniofacial } \\
\text { dysmorphic features. }\end{array}$ & $\begin{array}{l}\text { Low birth weight/ } \\
\text { length, VSD, } \\
\text { hydronephrosis, } \\
\text { Feeding difficulty, } \\
\text { speech delay, short } \\
\text { stature, relative } \\
\text { macrocephaly, } \\
\text { abnormal teeth, } \\
\text { 5th finger clinodactyly }\end{array}$ & $\begin{array}{l}\text { Short stature } \\
\text { triangular face, } \\
\text { moderate protruding } \\
\text { forehead, relative } \\
\text { macrocephaly, fifth } \\
\text { toe buckling and } \\
\text { irregularly teeth. }\end{array}$ \\
\hline
\end{tabular}

$A F$ amniotic fluid, IUGR intrauterine growth retardation, PNGR post-natal growth retardation, SGA small for gestational age, VSD ventricular septal defect, $B A D$ bone age delayed

athe percentage in table stand for the mosaicism level 


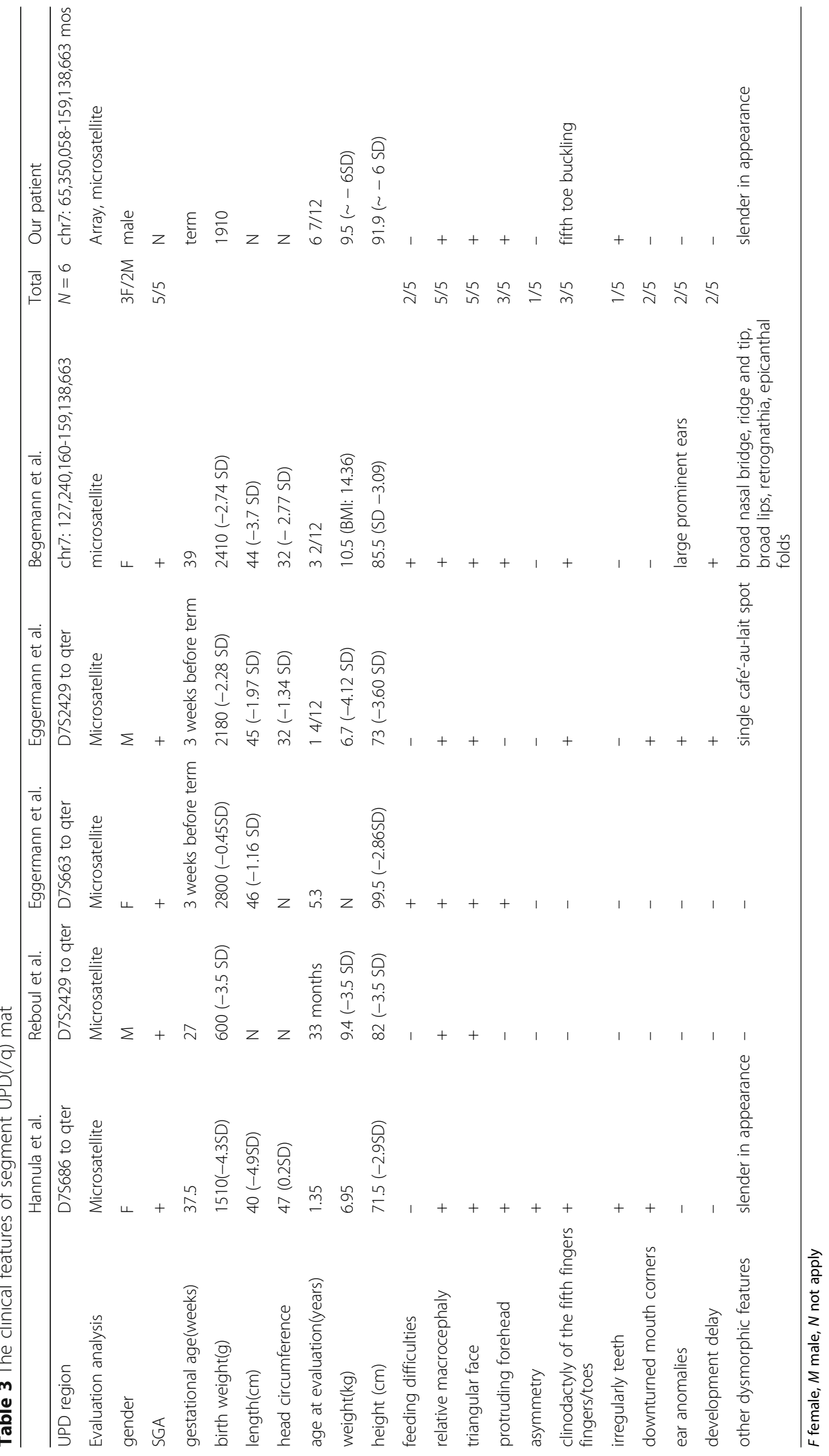




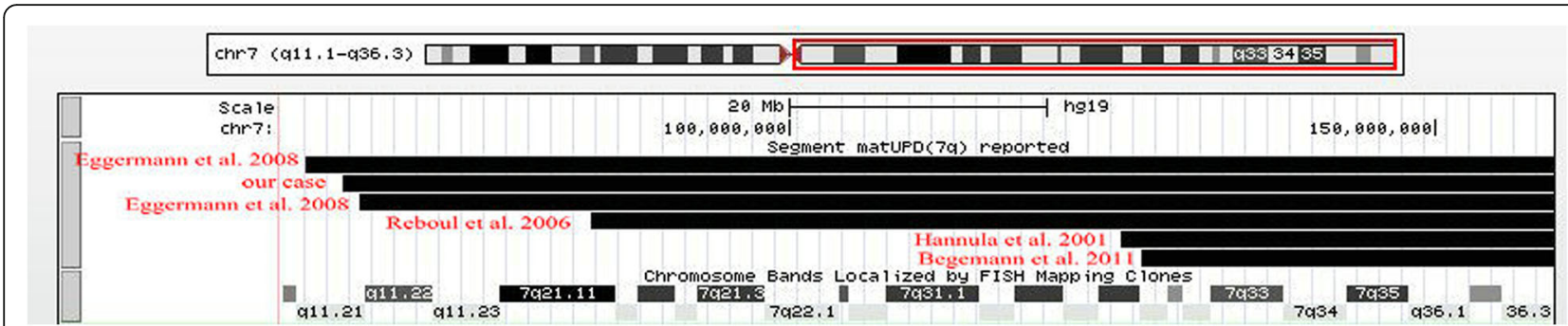

Fig. 3 Schematic representation referred to segment mat UPD(7q) cases reported (UCSC genome browser custom track, hg19)

We detected and confirmed the mosaicism by both microsatellite and SNP array, the formulation to calculated the mosaic level proposed by Bliek et al. [29] by STR maker may be not accurate [30]. The pattern of B allele by SNP array offered an alternative and probable more accurate method for mosaic level assessment. Correlation between the level of mosaicism and SRS phenotype should be performed when more such cases are detected.

Complex and segmental UPD could resulting from either meiotic, mitotic, or meiotic and subsequent mitotic abnormal recombinations. Interestingly, apart from full upid(7)mat mosaicism which was likely result from mitotic non-disjunction and subsequent trisomy rescue, our case present the existence of normal cell line and UPD(7q11-qter) cell line, indicate the mosaicism may arise from somatic recombination [31, 32], further study would need to prove this hypothesis. Meanwhile, mosaicism could be tissue specific, but no more research for other tissue of our patient was performed because the father did not gave the consent.

\section{Conclusions}

In summary, we described a second case with rare segmental maternal UPD(7q11-qter) mosaicism. This was the first report of UPD(7q11-qter) mosaicism detected by SNP array. Our case support the notion that there are genes control postnatal growth on long arm of chromosome 7 and indicate that $\sim 80 \%$ of $7 \mathrm{q} 11$-qter mosaicism level was contributed to the SRS phenotype.

\section{Abbreviations}

AF: Amniotic fluid; BL: Birth length; BW: Birth weight; CMA: Chromosome microarray analysis; IUGR: Intrauterine growth retardation; matUPD(7): Maternal uniparental disomy of chromosome 7; PNGR: Post-natal growth retardation; SD: Standard deviation; SGA: Small for gestational age; SNP: Single nucleotide polymorphisms; SRS: Silver-russell syndrome; UPD: Uniparental disomy

\section{Acknowledgments}

We thank the family for their support and all authors work in this study.

\section{Funding}

This work is supported by the project of science and technology of Guangxi Zhuang Autonomous Region (gui-ke-gong 14,124,004-1-8).

Availability of data and materials

Please contact authors for data requests.

\section{Authors' contributions}

Wrote the manuscript: JSS, YPS. Conceived and designed the experiments: XF, YPS. Performed the experiments: JSS, CYF and SJZ. XF, JSL, JW, TTJ were involved in SNP array analysis. CL and DHL helped to revise the manuscript. All authors read and approved the final manuscript.

Ethics approval and consent to participate

Written informed consent was obtained from the parents of the proband for publication of this Case Report and any accompanying images. The consent form was approved by the ethical committee of Guangxi Maternal and Child Health Hospital, China.

\section{Consent for publication}

The patient and guardian give their consent for images (such as face and clinical feature) or other clinical information relating to this case to be reported for academic purpose.

\section{Competing interests}

The authors declare that they have no competing interests.

\section{Publisher's Note}

Springer Nature remains neutral with regard to jurisdictional claims in published maps and institutional affiliations.

\section{Author details}

${ }^{1}$ Department of Genetic and Metabolic Central Laboratory, Guangxi Maternal and Child Health Hospital, Guangxi Birth Defects Prevention and Control Institute, No 59, Xiangzhu Road, Nanning, China. ${ }^{2}$ Department of Laboratory Medicine, Boston Children's Hospital, Harvard Medical School, 300 Longwood Avenue, Boston, MA 02115, USA.

Received: 9 September 2017 Accepted: 12 October 2017

Published online: 17 October 2017

\section{Reference}

1. Silver HK, et al. Syndrome of congenital hemihypertrophy, shortness of stature, and elevated urinary gonadotropins. Pediatrics. 1953;12(4):368-76.

2. Russell A. A syndrome of intra-uterine dwarfism recognizable at birth with cranio-facial dysostosis, disproportionately short arms, and other anomalies (5 examples). Proc R Soc Med. 1954;47(12):1040-4.

3. Azzi $\mathrm{S}$, et al. A prospective study validating a clinical scoring system and demonstrating phenotypical-genotypical correlations in silver-Russell syndrome. J Med Genet. 2015;52(7):446-53.

4. Bartholdi D, et al. Epigenetic mutations of the imprinted IGF2-H19 domain in silver-Russell syndrome (SRS): results from a large cohort of patients with SRS and SRS-like phenotypes. J Med Genet. 2009;46(3):192-7.

5. Netchine I, et al. 11p15 imprinting center region 1 loss of methylation is a common and specific cause of typical Russell-silver syndrome: clinical scoring system and epigenetic-phenotypic correlations. J Clin Endocrinol Metab. 2007:92(8):3148-54

6. Price SM, et al. The spectrum of silver-Russell syndrome: a clinical and molecular genetic study and new diagnostic criteria. J Med Genet. 1999;36(11):837-42.

7. Eggermann T, et al. Broad clinical spectrum in silver-Russell syndrome and consequences for genetic testing in growth retardation. Pediatrics. 2009;123(5):e929-31. 
8. Spence JE, et al. Uniparental disomy as a mechanism for human genetic disease. Am J Hum Genet. 1988;42(2):217-26.

9. Preece MA, et al. An analysis of the distribution of hetero- and isodisomic regions of chromosome 7 in five mUPD7 silver-Russell syndrome probands. J Med Genet. 1999;36(6):457-60.

10. Eggerding $F A$, et al. Uniparental isodisomy for paternal $7 p$ and maternal $7 q$ in a child with growth retardation. Am J Hum Genet. 1994;55(2):253-65.

11. Riesewijk AM, et al. Monoallelic expression of human PEG1/MEST is paralleled by parent-specific methylation in fetuses. Genomics. 1997;42(2):236-44.

12. Blagitko $\mathrm{N}$, et al. gamma2-COP, a novel imprinted gene on chromosome 7q32, defines a new imprinting cluster in the human genome. Hum Mol Genet. 1999;8(13):2387-96.

13. Yoshihashi $\mathrm{H}$, et al. Imprinting of human GRB10 and its mutations in two patients with Russell-silver syndrome. Am J Hum Genet. 2000;67(2):476-82.

14. Reboul MP, et al. Mosaic maternal uniparental isodisomy for chromosome 7q21-qter. Clin Genet. 2006;70(3):207-13.

15. Ishida M. New developments in silver-Russell syndrome and implications for clinical practice. Epigenomics. 2016;8(4):563-80.

16. Wakeling EL, et al. Diagnosis and management of silver-Russell syndrome: first international consensus statement. Nat Rev Endocrinol. 2017;13(2):105-24.

17. Conlin LK, et al. Mechanisms of mosaicism, chimerism and uniparental disomy identified by single nucleotide polymorphism array analysis. Hum Mol Genet. 2010;19(7):1263-75.

18. Liehr T. Cases with uniparental disomy. 2017. http://upd-tl.com/upd.html. Accessed 10/10/2017.

19. Monk $\mathrm{D}$, et al. Chromosome 7p disruptions in silver Russell syndrome: delineating an imprinted candidate gene region. Hum Genet. 2002;111(4-5):376-87.

20. Bilimoria $\mathrm{KY}$, Rothenberg JM. Prenatal diagnosis of a trisomy $7 /$ maternal uniparental heterodisomy 7 mosaic fetus. Am J Med Genet A. 2003;1 18A(1):60-3.

21. Miozzo M, et al. Post-zygotic origin of complete maternal chromosome 7 isodisomy and consequent loss of placental PEG1/MEST expression. Placenta. 2001:22(10):813-21.

22. Flori E, et al. Trisomy 7 mosaicism, maternal uniparental heterodisomy 7 and Hirschsprung's disease in a child with silver-Russell syndrome. Eur J Hum Genet. 2005;13(9):1013-8.

23. Fuke-Sato $\mathrm{T}$, et al. Mosaic upd(7)mat in a patient with silver-Russell syndrome. Am J Med Genet A. 2012;158A(2):465-8.

24. Hannula K, et al. A narrow segment of maternal uniparental disomy of chromosome 7q31-qter in silver-Russell syndrome delimits a candidate gene region. Am J Hum Genet. 2001;68(1):247-53.

25. Eggermann T, et al. Segmental maternal UPD(7q) in silver-Russell syndrome Clin Genet. 2008;74(5):486-9.

26. Begemann $M$, et al. Segmental maternal uniparental disomy $7 q$ associated with DLK1/GTL2 (14q32) hypomethylation. Am J Med Genet A. 2012; 158A(2):423-8

27. Monk D, et al. Duplication of 7p11.2-p13, including GRB10, in silver-Russell syndrome. Am J Hum Genet. 2000;66(1):36-46.

28. Joyce CA, et al. Duplication of 7p12.1-p13, including GRB10 and IGFBP1, in a mother and daughter with features of silver-Russell syndrome. Hum Genet. 1999;105(3):273-80.

29. Bliek J, et al. Increased tumour risk for BWS patients correlates with aberrant $\mathrm{H} 19$ and not KCNQ1OT1 methylation: occurrence of KCNQ1OT1 hypomethylation in familial cases of BWS. Hum Mol Genet. 2001:10(5):467-76.

30. Russo S, et al. A fluorescent method for detecting low-grade 11 patUPD mosaicism in Beckwith-Wiedemann syndrome. Mol Cell Probes. 2003;17(6):295-9.

31. Kotzot D. Complex and segmental uniparental disomy (UPD): review and lessons from rare chromosomal complements. J Med Genet. 2001;38(8):497-507

32. Chantot-Bastaraud S, et al. Formation of upd(7)mat by trisomic rescue: SNP array typing provides new insights in chromosomal nondisjunction. Mol Cytogenet. 2017;10:28.

33. Li H, et al. Height and weight standardized growth charts for Chinese children and adolescents aged 0 to 18 years. Zhonghua Er Ke Za Zhi. 2009; 47(7):487-92.

34 Kotzot D. Maternal uniparental disomy 7 and silver-Russell syndrome clinical update and comparison with other subgroups. Eur J Med Genet. 2008:51(5):444-51.

35 Hannula K, et al. Do patients with maternal uniparental disomy for chromosome 7 have a distinct mild silver-Russell phenotype? J Med Genet. 2001;38(4):273-8

36 Fuke T, et al. Molecular and clinical studies in 138 Japanese patients with silver-Russell syndrome. PLoS One. 2013;8(3):e60105.

\section{Submit your next manuscript to BioMed Central and we will help you at every step:}

- We accept pre-submission inquiries

- Our selector tool helps you to find the most relevant journal

- We provide round the clock customer support

- Convenient online submission

- Thorough peer review

- Inclusion in PubMed and all major indexing services

- Maximum visibility for your research

Submit your manuscript at www.biomedcentral.com/submit
Biomed Central 